\title{
Cesarean Section Scar Defect: Emerging Cause of Menstrual Irregularities-Case Series and Review of Literature
}

\author{
${ }^{1}$ Ashwini Harish Pai, ${ }^{2}$ Sreelakshmi Kodandapani
}

\begin{abstract}
Cesarean section (CS) is the most common surgery in women of reproductive age group. We report three cases of cesarean section scar defect who presented to us with severe dysmenorrhea, menorrhagia, and postmenstrual bleeding. Diagnosis was made at transvaginalsonography (TVS). Laparotomy and repair of this defect resulted in relief of symptoms. Scar defect is a rare late complication of cesarean section leading to menstrual irregularity. Transvaginalsonography helps in detection and also defines the thickness and length of defect. Conservative surgical correction of the defect followed by menstrual suppression helps in relief of symptoms and can be considered as the first line in management.
\end{abstract}

Keywords: Cesarean section, Laparotomy, Scar defect, Transvaginalsonography.

How to cite this article: Pai $\mathrm{AH}$, Kodandapani S. Cesarean Section Scar Defect: Emerging Cause of Menstrual IrregularitiesCase Series and Review of Literature. Int J Infertil Fetal Med 2016;7(1):27-31.

Source of support: Nil

Conflict of interest: None

Date of received: $21-10-2015$

Date of acceptance: 14-02-2016

Date of publication: April 2016

\section{INTRODUCTION}

Cesarean section (CS) is the most common surgery in women of reproductive age group. A primary CS is the most common indication for a repeat CS. The gynecologic sequelae due to deficient uterine scar healing are recently being identified and described. The proposed mechanism of this abnormal uterine bleeding is a pouch or "isthmocele"1,2 at lower uterine segment. The prevalence of reported symptomatic or clinically relevant cesarean scar defects (CSDs) ranges from 0.3 to $19 \%{ }^{3}$

\footnotetext{
${ }^{1}$ Associate Professor, ${ }^{2}$ Professor

1,2Department of Obstetrics and Gynecology, Subbaiah Institute of Medical Sciences, Shimoga, Karnataka, India

Corresponding Author: Ashwini Harish Pai, Associate Professor, Department of Obstetrics and Gynecology, Subbaiah Institute of Medical Sciences, Shimoga, Karnataka, India Phone: +919945671221, e-mail: ashwinim78@rediffmail.com
}

\section{Case Series}

Case 1

Mrs A, a 28-year-old para two with previous two lower segment cesarean deliveries, last delivery being 2 years back, presented with menorrhagia and severe dysmenorrhea affecting her daily routine activities. Clinical examination showed no positive findings. On transvaginalsonography (TVS), a full thickness lower segment CSD was noted (Fig. 1). Laparotomy was performed and defect was repaired with no 1-0 vicryl in two layers of continuous interlocking sutures (Fig. 2). Menstrual suppression was done for 3 months with continuous low-dose combined oral contraceptive pills. On TVS (Fig. 3) after 3 months, repaired site was healthy with no defect. At 6 months follow-up, patient was asymptomatic.

\section{Case 2}

Mrs B, a 30-year-old para two with both lower segment cesarean deliveries, the last being 8 years back, presented with severe dysmenorrhea and chronic lower abdominal pain for 2 years. She was empirically treated for recurrent urinary tract infection with no relief. Clinical examination was unremarkable. Transvaginalsonography showed full thickness, partial length scar dehiscence at cesarean scar site. Defect was sutured by laparotomy (Fig. 4) and menstrual suppression was done for 3 months similar to case 1 . Patient was symptomatically better at 5 months, although we noticed persistent $5 \mathrm{~mm}$ partial thickness scar defect even after 9 months.

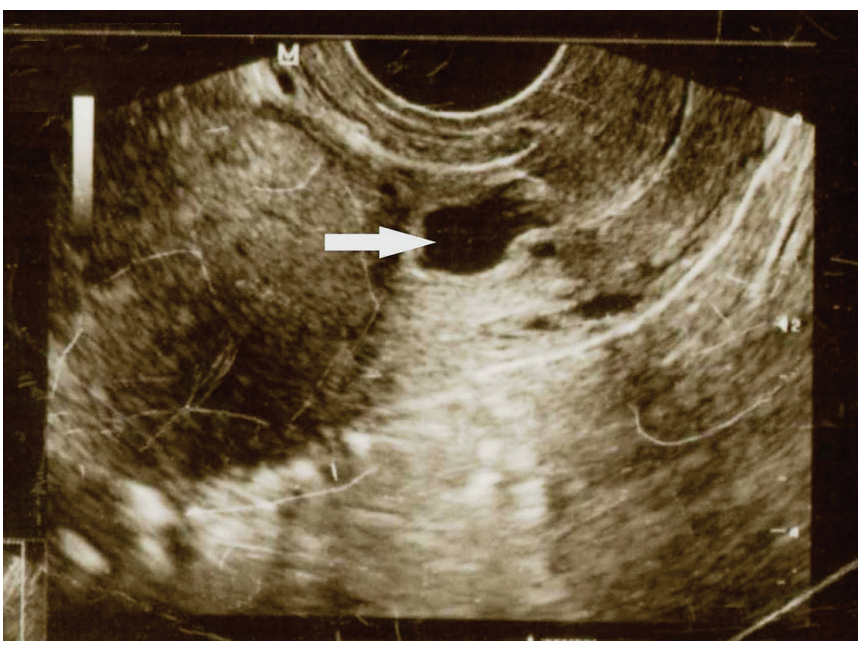

Fig. 1: Case 1-Full thickness cesarean scar defect 

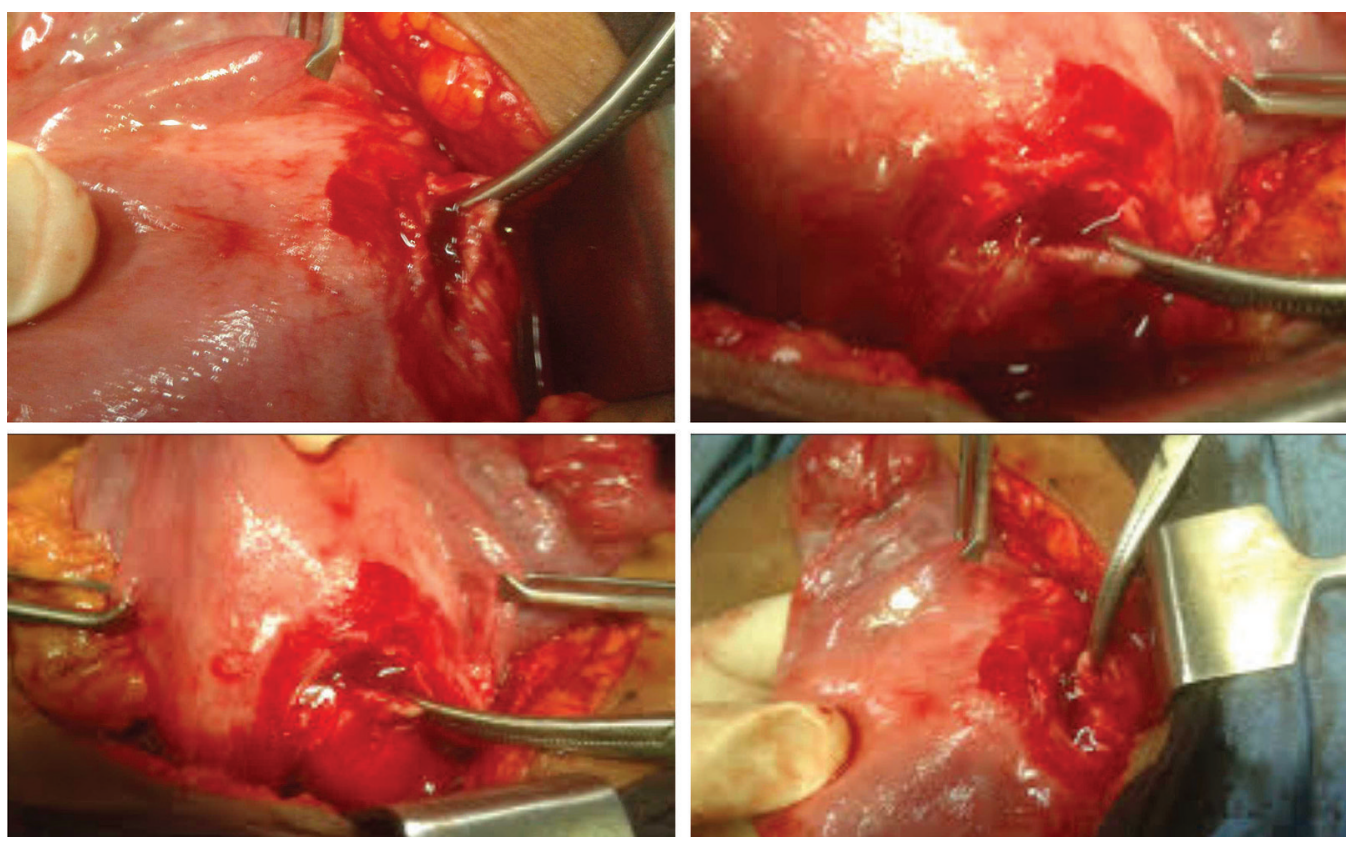

Fig. 2: Case 1-Intraoperative findings

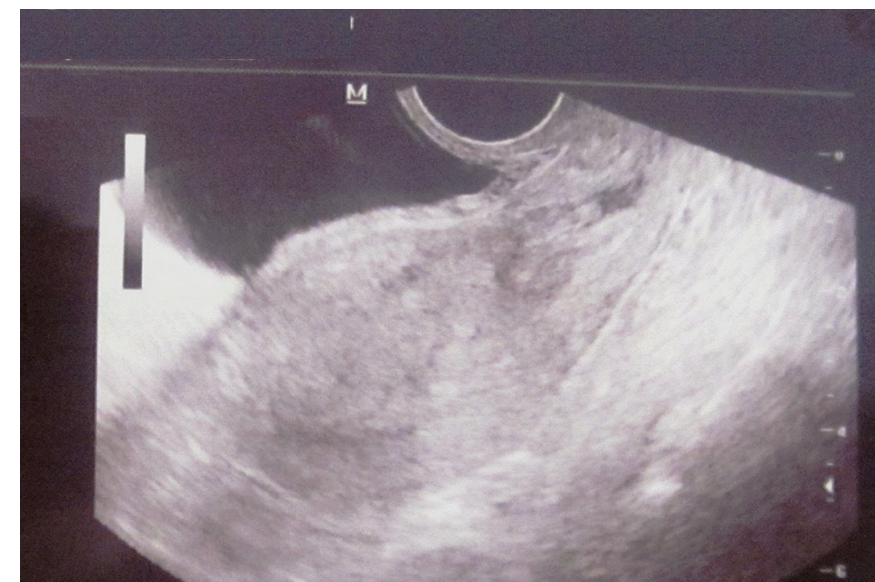

Fig. 3: Transvaginalsonography postsurgical repair follow-up

\section{Case 3}

Mrs C, a 28-year-old para two with two lower segment cesarean deliveries, presented with chronic lower abdominal pain, vaginal discharge, menorrhagia, postmenstrualbleeding, dyspareunia, and contact bleeding for 3 years. She was symptomatically treated with no relief. She had been advised hysterectomy on basis of probable diagnosis of a degenerated fibroid on transabdominal ultrasound. Bulky mobile uterus with tenderness was noted at bimanual palpation. Transvaginalsonography (Fig. 5) revealed a large, full thickness CSD of $3 \mathrm{~cm}$ with menstrual debris seen floating into the defect. Laparotomy with repair of the scar defect was done after a course of
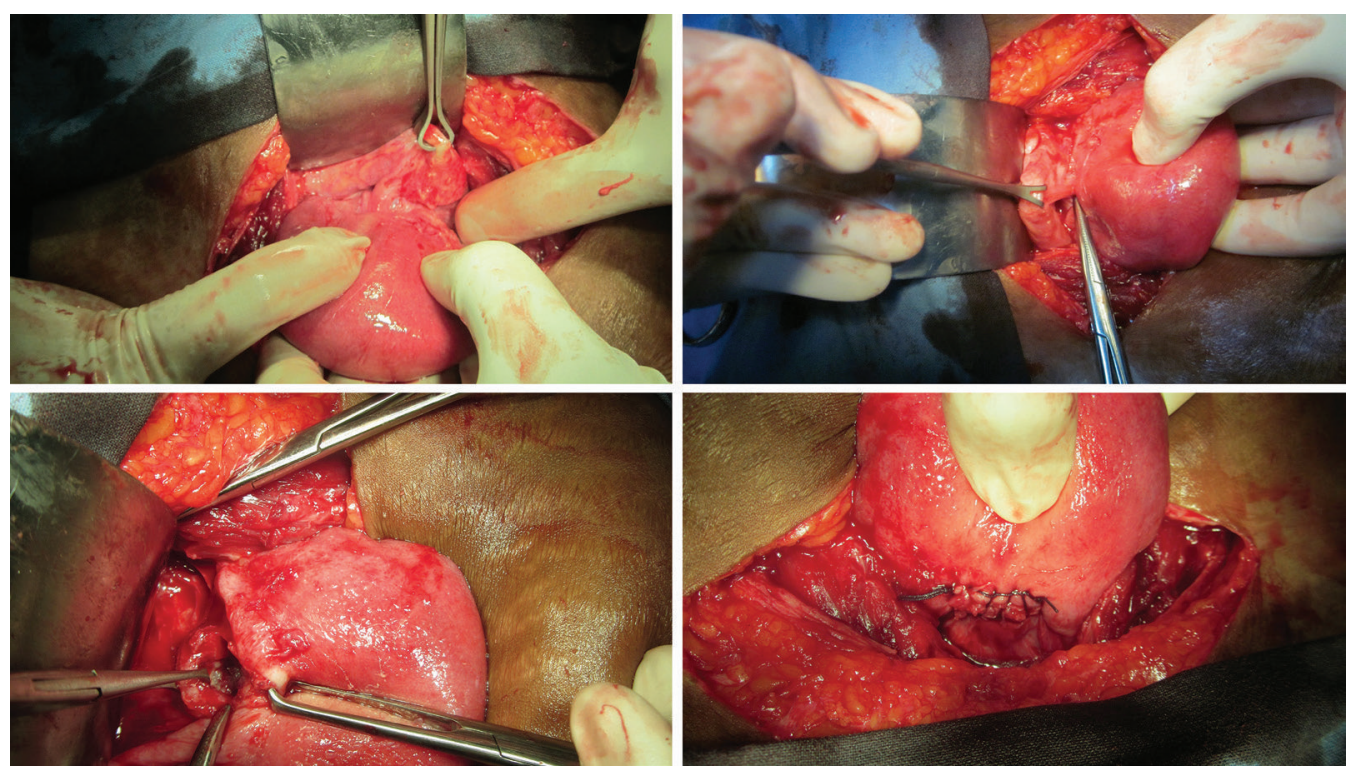

Fig. 4: Case 2-Intraoperative findings 


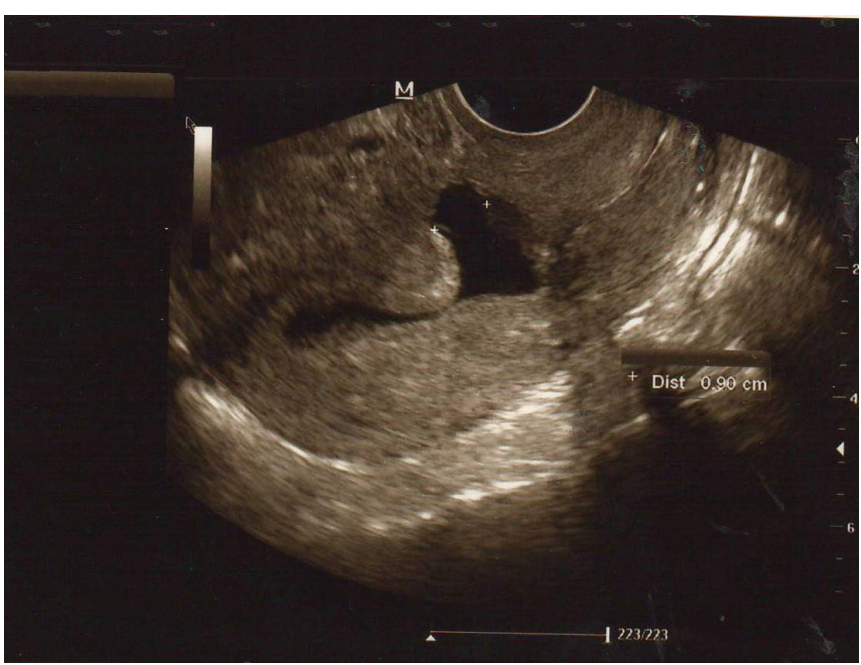

Fig. 5: Case 3-Full thickness cesarean scar defect

antibiotics. Menstrual suppression was done for 3 months similarly. At 3 months follow-up, defect had healed and she was asymptomatic. However, she returned after 9 months with worsened symptoms, and on TVS, the scar defect was found to be reopened.

\section{DISCUSSION}

Clinically, relevant CSDs have recently become more obvious. A wide range in the prevalence of CSD (56-84\%) has been found in a random population of women with previous lower segment cesarean section using contrastenhanced sonohysterogram. ${ }^{4}$ However, the reported

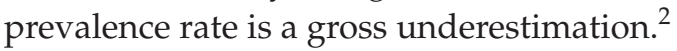

Isthmocele may be attributed to technique of uterine closure, development of lower uterine segment, location of the incision, wound healing, and miscellaneous factors. ${ }^{1-4}$ As various studies have evaluated different risk factors, it is difficult to compare them or reach a consensus. Possible risk factors are single-layer myometrial closure, labor before CS, multiple CS, and uterine retroflexion. Probably, the most ischemic technique and the slowest reabsorbable suture would be the worst combination. ${ }^{5}$ No association was found between period of cesarean delivery and onset of symptoms. Multiple CS and retroflexed uterus contribute to larger scar defects in depth and width. ${ }^{3}$ This has been attributed to reduced vascular perfusion and tension at incision site that interferes with healing. The larger the defect, more pronounced were the symptoms. This was evident in our patients in whom case 3 was more symptomatic than the others probably due to a larger defect. As all our patients had their cesarean delivery elsewhere, there were no data available regarding labor, uterine closure technique, and use of suture materials.

Late sequelae ${ }^{1}$ of cesarean delivery include conditions such as abnormal bleeding, pelvic pain, infertility, and cesarean scar ectopic pregnancy, as well as a potentially higher risk of complications and difficulties during gynecologic procedures such as uterine evacuation, hysterectomy, endometrial ablation, and insertion of an intrauterine device.

Young women with previous CS deliveries report to gynecologic outpatient department with various menstrual problems such as menorrhagia, severe dysmenorrhea, postmenstrual spotting, intermenstrual bleeding, and chronic abdominal pain. Wang et $\mathrm{al}^{3}$ found that among the 293 patients diagnosed with CSD by TVS, the most common symptom was intermenstrual spotting (64\%), followed by dysmenorrhea (53\%), chronic pelvic pain $(40 \%)$, and dyspareunia $(18 \%)$. There are no other causes for these symptoms in these women. They have been misdiagnosed with conditions such as recurrent urinary tract infections, pelvic inflammatory disease, and were treated for the same. Also, hysterectomy was performed for want of symptomatic relief and lack of definite diagnosis.

Young women with menstrual problems need to be evaluated in detail. Detailed history taking and clinical examination is essential. Transvaginal ultrasound is a valuable tool for diagnosis of CSDs and to rule out other causes of menstrual problems. Cesarean scar defects are defined as a wedge-shaped cystic, anechoic, or hypoechoic distortion in the presumed scar region in the nonpregnant state and have been reported in the literature using various imaging modalities. It was first described using hysterosalpingography in 1961, transabdominalsonography (TAS) in $1982,{ }^{7}$ and TVS in $1990 .^{8}$

The CS scar should be well delineated as a hypoechoic indentation at the anterior wall of the LUS, measurable in three dimensions, and lying between the uterovesical fold and the internal cervical os. ${ }^{9}$ The best time during the cycle to identify the pouch with sonography was during the bleeding episode, usually a few days after the menses, because the principal symptom was postmenstrual spotting. ${ }^{5}$ In cases of previous elective CS, the scar will appear halfway between the uterovesical fold and the internal cervical os, while, following emergency CS, the scar could well be below, or at the level of the os. Small symptomatic defects may be missed on transabdominal ultrasound. In all of our cases, initial diagnosis of CSDs was missed at previous consultations elsewhere because only transabdominal ultrasound was done. Case 3 was diagnosed to have cystic degenerated fibroid and was advised hysterectomy.

In TVS, menstrual debris and blood may act as a contrast medium for diagnosis of scar defects. Apparent scar "defects" are seen more often, appear to be 
larger, and have clearer margins when saline contrast sonohysterography ${ }^{10}$ or gel instillation sonography is used. However, increased uterine pressure associated with this procedure may exaggerate the size of any scar present and may also increase prevalence of CSDs.

Diagnostic hysteroscopy showed high correlation with TVS in detection of a pouch in region of cesarean scar. ${ }^{5,11}$ Hence, TVS is very simple, noninvasive, low-cost procedure that also helps rule out other causes. However, quantification of CSDs and correlation of defect size with symptoms still remains a challenge.

Symptomatic relief and preservation of uterus is the goal of managing these women. Repair of the defect has been done by laparotomy, laparoscopy, and also by robotic surgery. Schepker et $\mathrm{al}^{11}$ performed microsurgical uterine reconstruction by minilaparotomy and found symptomatic relief in all their patients and also improvement in fertility. This correlates with our patients in whom we performed laparotomy and repair of the defect. All of them showed symptomatic relief at 4 to 6 months postcorrection. Though there was residual defect seen, the patients were seen to be devoid of symptoms on follow up. This pauciness in healing may be attributed to increased interval between last cesarean and defect repair.

Marotta et $\mathrm{al}^{12}$ evaluated CSDs using TVS and magnetic resonance imaging (MRI) and did laparoscopic surgical repair of CSDs, which included fibrotic excision and closure of the defect. They found that this procedure showed an improvement in anatomic and functional outcome. La Rosa et $\mathrm{al}^{13}$ have performed robotic laparoscopic repair on a patient with CSD and found it to give excellent postoperative results. Ida et $\mathrm{al}^{14}$ treated a patient conservatively with repeated lavage of the wound dehiscence using physiological saline solution by Hyscatheter and recorded healing of the defect. Prolonged menstrual suppression with monophasic pills has also been attempted. Varied success in terms of relief of symptoms, subsequent conception, and delivery has been reported in different studies.

A histopathological study by Morris ${ }^{15}$ of hysterectomy specimens with CS scars proposed firstly the presence of a congested endometrial fold and small polyps in the scar recess, which are potential causes of menorrhagia and abnormal uterine bleeding; secondly, lymphocytic infiltration and distortion of the lower uterine segment could contribute to chronic pelvic pain and dyspareunia; and thirdly, iatrogenic adenomyosis confined to the scar could account for dysmenorrhea. Histopathology of excised scar tissue in case 1 and 2 showed no evidence of scar adenomyosis or polyp. Only, leucocytic infiltration was noted.

\section{CONCLUSION}

Scar defects are late sequelae of CS, leading to menstrual irregularities and pain abdomen. Transvaginal ultrasound helps in diagnosis, and in noting extent of the defect. Conservative surgical correction of the defect followed by menstrual suppression helps in relief of symptoms and can be considered as the first line in management. However, there needs to be a consensus regarding definition, diagnosis, and management of these emerging phenomena of CSDs.

\section{REFERENCES}

1. Tower AM, Frishman GN. Cesarean scar defects: an underrecognized cause of abnormal uterine bleeding and other gynecologic complications. J Minim Invasive Gynecol 2013 Sep-Oct;20(5):562-572.

2. Gubbini G, Casadio P, Marra E. Resectoscopic correction of the "isthmocele" in women with postmenstrual abnormal uterine bleeding and secondary infertility. J Minim Invasive Gynecol 2008 Mar-Apr;15(2):172-175.

3. Wang CB, Chiu WC, Lee CY, Sun YL, LinYH, Tseng CJ. Cesarean scar defect: correlation between cesarean section number, defect size, clinical symptoms and uterine position. Ultrasound Obstet Gynecol 2009 Jul;34(1):85-89.

4. Bij de Vaate AJ, van der Voet LF, Naji O, Witmer M, Veersema S, Brölmann HA, Bourne T, Huirne JA. Prevalence, potential risk factors for development and symptoms related to the presence of uterine niches following cesarean section: systematic review. Ultrasound Obstet Gynecol 2014 Apr;43(4): 372-382.

5. Fabres C, Aviles G, De la Jara C, Escalona J, Munoz JF, Mackenna A, Fernandez C, Zegers-Hochschild F, Fernandez E. The cesarean delivery scar pouch: clinical implications and diagnostic correlation between transvaginal sonography and hysteroscopy. J Ultrasound Med 2003 Jul;22(7): 695-700.

6. Poidevin LO. The value of hysterography in the prediction of cesarean section wound defects. Am J Obstet Gynecol 1961 Jan;81:67-71.

7. Burger NF, Darazs B, Boes EG. An echographic evaluation during the early puerperium of the uterine wound after caesarean section. J Clin Ultrasound 1982 Jul-Aug;10(6): 271-274.

8. Chen HY, Chen SJ, Hsieh FJ. Observation of cesarean section scar by transvaginal ultrasonography. Ultrasound Med Biol 1990;16(5):443-447.

9. Naji O, Abdallah Y, Bij De Vaate AJ, Smith A, Pexsters A, Stalder C, McIndoe A, Ghaem-Maghami S, Lees C, Brölmann HAM, et al. Standardized approach for imaging and measuring cesarean section scars using ultrasonography. Ultrasound Obstet Gynecol 2012 Mar;39(3):252-259.

10. Osser OV, Jokubkiene L, Valentin L. Cesarean section scar defects: agreement between transvaginalsonographic findings with and without saline contrast enhancement. Ultrasound Obstet Gynecol 2010 Jan;35(1):75-83.

11. Schepker N, Garcia-Rocha GJ, von Versen-Hoynck F, Hillemanns P, Schippert C. Clinical diagnosis and therapy of uterine scar defects after caesarean section in non-pregnant women. Arch Gynecol Obstet 2015 Jun;291(6):1417-1423. 
12. Marotta ML, Donnez J, Squifflet J, Jadoul P, Darii N, Donnez O. Laparoscopic repair of post-cesarean section uterine scar defects diagnosed in nonpregnant women. J Minim Invasive Gynecol 2013 May-Jun;20(3):386-391.

13. La Rosa MF, McCarth S, Richter C, Azodi M. Robotic repair of uterine dehiscence. JSLS 2013 Jan-Mar;17(1): 156-160.
14. Ida A, Kubota Y, Nosaka M, Ito K, Kato H, Tsuji Y. Successful management of a cesarean scar defect with dehiscence of the uterine incision by using wound lavage. Case Rep Obstet Gynecol 2014;2014:421014.

15. Morris H. Surgical pathology of the lower uterine segment cesarean section scar: is the scar a source of clinical symptoms? Int J Gynecol Pathol 1995 Jan;14(1):16-20. 